

\section{O ICMS Ecológico como uma política de incentivo dos gastos ambientais municipais}

\section{Ecological ICMS as a policy incentive for municipal environmental expenses}

\author{
Biancca Scarpeline de Castro* \\ Lucas de Almeida Nogueira da Costa**
}

\section{Resumo}

O ICMS Ecológico (ICMS-E) é uma política pública regulatória utilizada como mecanismo de coordenação entre os interesses dos estados e as ações dos municípios, com vistas a estimular e premiar práticas ambientais adequadas. Esse artigo tem como objetivo verificar se essa política é efetiva para a adoção de práticas sustentáveis pelos municípios, medidas a partir dos gastos ambientais. Para tal, foi efetuada uma análise no período 2012-2016 comparando os gastos em gestão ambiental como proporção das despesas totais liquidadas com a razão entre o volume recebido do ICMS-E e a receita fiscal total de cada município. Foi comprovada a correlação positiva entre os gastos em gestão ambiental e os recursos de ICMS-E recebidos pelo município. Contudo, o gasto ambiental aumenta relativamente pouco em função do incremento do ICMS-E na receita, e essa relação fica mais nítida nos municípios que recebem proporcionalmente mais ICMS-E. Verificou-se que o índice de desenvolvimento humano (IDH-M) e a população do município também afetam a proporção de gastos em gestão ambiental. Um resultado particularmente importante é que o desenho da legislação estadual influencia a resposta dos municípios: quanto maior o prêmio percebido pelas prefeituras em função da melhoria de seu desempenho ambiental, maior tende a ser seu esforço em adotar ações de gestão ambiental. Demonstra-se, assim, que a coordenação entre os instrumentos econômicos estatais e as ações municipais podem exercer papel relevante para tornar a gestão pública mais sustentável.

Palavras-chave: ICMS Ecológico, gastos municipais, política ambiental, coordenação federativa.

\author{
Doniel Sonder Costa ${ }^{* * *}$ \\ Corlos Eduardo Frickmonn Young ${ }^{* * * *}$
}

\begin{abstract}
The objective of this paper is to verify if the Ecological ICMS (ICMS-E) is an effective policy for the adoption of sustainable practices by the Brazilian municipalities, measured from environmental expenditures. To this end, an analysis was performed in the period 2012-2016 comparing municipal expenditures on environmental management as a proportion of the total expenses settled with the ratio between the volume received from the ICMS-E and the total tax revenue of each municipality. The positive correlation between the environmental management expenditures and the ICMS-E resources received by the municipality was verified. However, environmental spending increases relatively little as a result of the increase in ICMS-E in revenue, and this relationship becomes clearer only for municipalities that receive proportionally more ICMS-E. It was verified that the human development index (HDI-M) and the population of the municipality also affect the proportion of expenditures on environmental management. One particularly important result is that the design of state legislation influences the response of municipalities: the higher the premium perceived by municipalities due to the improvement of their environmental performance, the greater the effort to adopt environmental management actions. It is shown, therefore, that economic instruments can play a relevant role in making public management more sustainable.
\end{abstract}

Keyword: Ecological ICMS, municipal spending, environmental policy, federal coordination

\footnotetext{
*Professora da Universidade Federal Rural do Rio de Janeiro. E-mail: bianccastro2@gmail.com

**Instituto de Economia, Universidade Federal do Rio de Janeiro. E-mail: Lucas.an.costa@gmail.com

***Graduação em Ciências Economias, UFRRJ. E-mail: danielsanderc@gmail.com

****Professor do Instituto de Economia, Universidade Federal do Rio de Janeiro.

E-mail: carloseduardoyoung@gmail.com
} 


\section{INTRODUÇÃO}

Olmposto porCirculação deMercadoriasePrestação de ServiçosEcológico(ICMS-E), também chamado de ICMS Verde, é uma política pública regulatória desenvolvida por alguns estados brasileiros com vistas a estimular e premiar os municípios que mantêm em seus territórios práticas ambientais consideradas adequadas pela legislação estadual. Não se trata de um novo imposto, mas de um incentivo fiscal que tem a vantagem de redistribuir a parcela dos recursos que já seriam transferidos para os municípios (cota-parte do ICMS) a partir do seu desempenho ambiental.

Os recursos municipais obtidos pelo repasse do ICMS-E não necessariamente são alocados em gastos ambientais, podendo ser usados para outros fins, como suplementar as contas municipais e realizar políticas sociais. Isso ocorre devido à desvinculação de gastos, característica das transferências tributárias, em que os municípios têm liberdade na alocação dos recursos, conforme suas prioridades e interesses.

Dado suas características, entende-se que o ICMS-E é utilizado com um mecanismo de coordenação entre os interesses dos estados e as ações dos entes municipais. Nesse sentido, ele seria capaz de gerar uma competição positiva entre os municípios que, para obter maiores verbas dos repasses estaduais, intentam cumprir os critérios ambientais, o que, teoricamente, aumentaria seus gastos com o tema.

Assim, esse estudo busca identificar a relação entre o ICMS-E recebido e a despesa ambiental municipal. A principal variável a ser explicada é o percentual das despesas liquidadas com a Função "Gestão Ambiental" sobre as despesas liquidadas totais dos municípios. As despesas liquidadas com tal função estão relacionadas à capacidade de um município estabelecer sistemas de gestão ambiental, e não incluem as despesas com saneamento, limpeza urbana e coleta de lixo, incluídas em outras funções governamentais.

$\mathrm{O}$ artigo divide-se em quatro itens, além desta introdução. $\mathrm{O}$ primeiro discute o ICMS-E como uma política pública capaz de promover a coordenação federativa entre estados e municípios. O segundo item apresenta a metodologia de pesquisa, baseada em análises estatísticas. O terceiro item expõe e analisa os resultados deste estudo e, no último, são realizadas as considerações finais.

\section{COORDENAÇÃO DE POLÍTICAS PÚBLICAS E ICMS ECOLÓGICO (ICMS-E) NO BRASIL}

O Brasil é uma federação, onde União, Estados e Municípios compartilham a soberania nacional, ao mesmo tempo em que são autônomos. Com essa autonomia, apesar das atribuições constitucionais, os entes podem definir suas próprias legislações (desde que verse sobre suas peculiaridades), autogovernar-se, administrarse, possuem capacidade de definir sobre suas políticas públicas e finanças. 
Dentre as políticas públicas que devem ser realizadas de forma compartilhada pelos entes federativos, estão as políticas ambientais (artigos 23 e 24 da Constituição Federal de 1988). Considera-se a concomitância da competência dos três entes federativos nesta matéria adequada, pois o meio ambiente está, ao mesmo tempo, no espaço global e local. A competência compartilhada, no entanto, comporta o risco de que um passe ao outro a incumbência que lhe era devida e ninguém resolva o problema. Em adição, podem ocorrer ações sobrepostas ou contraditórias relacionadas à proteção ambiental (Castro \& Young, 2017).

Para evitar tais problemas podem ser utilizados diferentes mecanismos de coordenação entre as ações dos entes federativos. A coordenação se refere à disposição ordenada, coerente e metódica de determinado sistema, e pode ser definida como gerenciamento de interdependências entre atividades (Malone \&Crowston, 1994). O estudo da coordenação requer perguntar quais são os tipos de interdependência existentes entre as atividades, e como tais interdependências e atividades podem ser gerenciadas. Assim, a coordenação federativa se refere ao gerenciamento das atividades interdependentes entre os vários níveis do governo e suas políticas públicas.

Dentre as interdependências existentes entre os entes federativos é possível mencionar a questão fiscal. Devido às desigualdades, existentes em qualquer federação, mas bastante acentuadas no Brasil no que diz respeito ao ambiente econômico, foram criadas medidas compensatórias, como transferências de impostos que têm o objetivo redistribuir recursos entre os entes federativos (Maciel; Piza; Penoff, 2009). Essa proposta está ancorada no princípio de solidariedade, que impõe a partilha da riqueza entre os entes com o intuito de fortalecer sua autonomia política. Estudo da FIRJAN (2017) aponta que os Municípios, em sua maioria, ainda dependem de repasses dos outros entes para obter receitas correntes. Segundo o mesmo estudo, apenas 136 municípios, de um total de 4.544 analisados no Índice FIRJAN de Gestão Fiscal, conseguiram que mais de $40 \%$ de suas receitas fossem originárias de recursos próprios. Em outras palavras, os Municípios dependem dos recursos transferidos pela União e Estados para a realização de suas políticas públicas. Já os Estados e União dependem dos Municípios para que diversas políticas cheguem aos cidadãos, inclusive as ambientais. Contudo, ao se tratar das transferências, não há obrigação de que os Municípios usem esses recursos conforme os interesses dos outros entes federativos.

A coordenação federativa pode ser obtida por diferentes estratégias baseadas na cooperação e competição entre os entes, sendo que o mais adequado seria alcançar o equilíbrio entre elas (Abrucio, 2005).

A cooperação pode ser estimulada por meio da legislação que obrigue os atores a compartilhar decisões e tarefas, fomentando parcerias para resolver problemas públicos. Entretanto, para que isso ocorra, é necessária a construção de uma cultura política baseada no respeito mútuo e na negociação no plano intergovernamental, coisa incipiente no país (Abrucio, 2005). 
A competição também pode ser usada para alcançar a coordenação entre os diferentes níveis de governos. Primeiro, devido à importância dos controles mútuos como instrumento contra o domínio de um nível de governo sobre os demais. Além disso, a competição federativa pode favorecer a busca pela inovação e pelo melhor desempenho das gestões locais, já que os eleitores podem comparar os governantes. Entretanto, há problemas advindos de competições desmedidas, como a guerra fiscal, que afeta a solidariedade entre os entes (Abrucio, 2005).

É importante destacar que o acesso a informações e a capacidade de fazer garantir os contratos são relevantes para as estratégias aqui mencionadas, mas também para outros mecanismos para se atingir a coordenação, propostos por autores como Mintzberg (2008) que recomenda a utilização do ajuste mútuo, controle hierárquico e padronização; e Bouckaert, Peters e Verhoest (2010) que sugerem mecanismos baseados no mercado; hierarquia e acordos em rede. O mecanismo hierárquico, apontado pelos autores, merece destaque, pois na literatura existe a discussão sobre a necessidade de uma liderança para estimular a coordenação, com o objetivo de organizar as atividades interdependentes. Contudo, Metcalfe (1996) lembra que a aceitação de uma liderança pode não ser eficiente em regimes caracterizados por uma autonomia organizacional grande. Nesses casos, as organizações desenvolveriam uma capacidade de coordenação entre si em resposta ao aumento de sua interdependência. Esse último autor admite, no entanto, que um governo altamente coordenado é difícil de ser alcançado, dado que o Estado contém dentro de sua estrutura atores com interesses muito heterogêneos.

No Brasil, as desigualdades no sistema tributário impulsionam acordos e parcerias entre as esferas governamentais, pois dificilmente os entes contam com verbas suficientes para realizar políticas públicas sozinhos. Por outro lado, os Estados e, principalmente, a União cumprem o papel de líderes na busca da coordenação entre os diferentes entes federativos, principalmente por sua maior capacidade de arrecadação, transferências monetárias e financiamento, o que acaba subjugando outras unidades governamentais (Arretche, 2006). A liderança, em geral, é utilizada quando se pretende fomentar a competição com vistas a gerenciar as interdependências entre as atividades para alcançar objetivos comuns, por exemplo, a partir do estabelecimento de critérios para a redistribuição das transferências monetárias, como ocorre no ICMS-E.

O Imposto sobre Circulação de Mercadorias e Serviços é um imposto estadual regulado pelos artigos 155 e 158 da Constituição Federal de 1988, que determinam que $25 \%$ do montante total de ICMS arrecadado pelo estado devem ser transferidos aos seus municípios. Dessa parcela pertencente aos municípios, três quartos devem ser distribuídos de acordo com a proporção relativa ao valor adicionado nas operações de circulação de mercadorias e prestações de serviços gerados no território. Um quarto deve ser distribuído de acordo com a lei estadual, que tem autonomia para definir os critérios específicos para transferir o recurso. 
Aproveitando essa possibilidade, alguns estados incluíram critérios ambientais entre os parâmetros próprios para a distribuição de recursos do ICMS. De acordo com Loureiro (2002), essa proposta surgiu a partir de um movimento de municípios paranaenses que buscavam compensação financeira por terem boa parte de seu território caracterizado como áreas de proteção ambiental, reduzindo o potencial de outras atividades econômicas que gerassem dividendos. Assim, o Paraná foi pioneiro ao estabelecer critérios ambientais como medida para a distribuição do ICMS entre os seus municípios. A Lei Complementar Estadual N. 59/1991 definiu que os critérios ambientais relevantes para o estado seriam a existência no município de mananciais de abastecimento e Unidades de Conservação, e a Portaria Nº. 263/1998 do Instituto Ambiental do Paraná (IAP-PR) adicionou critérios como registro fundiário, tamanho, qualidade da área protegida e categoria de manejo como relevantes para os cálculos do repasse.

Após a criação do ICMS-E no Paraná, mais 16 estados elaboraram e aprovaram leis com essas mesmas propostas. A Paraíba, embora já possua legislação de ICMS-E (Lei №. 9.600/2011), até janeiro de 2018, não a implementou devido a questionamentos jurídicos sobre sua constitucionalidade.

Acredita-se que oICMS-E pode ser entendido como um mecanismo de coordenação federativa, pois adéqua as ações dos municípios aos interesses dos estados. Esse mecanismo, a depender da característica da sua legislação, usa a competição positiva entre os municípios por mais verbas estatais, a partir do atendimento dos critérios estipulados pelo estado.

Os estados definiram critérios ambientais bastante variados para a distribuição da cota-parte do ICMS. Dentre esses critérios é possível mencionar a existência de Unidades de Conservação, de mananciais de abastecimento de água, sistemas de coleta e reciclagem de lixo; características e qualidade da gestão ambiental, com foco na criação de Conselhos e Fundos Municipais de Meio Ambiente; bem como a existência de políticas ambientais de reflorestamento, de combate ao incêndio, entre outras.

A porcentagem da cota-parte do ICMS-E distribuída, bem como a forma de cálculo da distribuição dos recursos estaduais é bastante diversificada, com propostas de criação de rankings de desempenho, contabilização de critérios de qualidade ou importância das áreas a serem preservadas. Em alguns casos esses cálculos são de difícil compreensão, e a falta de transparência na divulgação da contabilidade, dos critérios e mesmo dos repasses, não favorece o envolvimento dos municípios nesta política.

O desconhecimento do ICMS-E pelos gestores municipais foi apontado por diferentes trabalhos (Ribeiro et. al, 2013; Uhlmann, 2010; Moreira, 2004) e tem sido enfrentado por vários estados que promovem oficinas e seminários para divulgar a política (Rio de Janeiro, Mato Grosso, Goiás, entre outros). Porém, outros estados ainda são foram efetivos nesta divulgação. 
Como um mecanismo de coordenação, o ICMS-E precisa ser publicizado, pois seu conhecimento garante o engajamento municipal. Em outras palavras, caso os estados não realizem ampla comunicação a respeito do ICMS ecológico, seus critérios, cálculos e repasses, ocorrerão menos incentivos para os municípios atenderem aos critérios ambientais estipulados, fazendo com que essa proposta seja inócua.

Com o objetivo de analisar as características dos critérios ambientais utilizados pelos estados para a partilha do ICMS-E, foi realizada uma pesquisa da legislação de cada estado que a implementou até 2018 (o que exclui a Paraíba). As características analisadas foram:

(i) Ano de criação da lei de ICMS-E;

(ii) A Porcentagem destinada ao ICMS-E;

(iii) O grau de adicionalidade (Alta, Média, Baixa ou Inexistente), entendido como a existência de incentivos aos municípios a aumentarem seus esforços de gestão ambiental, através de critérios quantitativos ou qualitativos, o que induz a uma competição positiva entre eles.

Uma legislação é classificada como de alta adicionalidade se adota critérios que premiam mais os municípios onde há melhor desempenho na gestão ambiental. Em contraste, em uma legislação de baixa adicionalidade, os critérios adotados pouco diferenciam os esforços municipais em melhorar seu desempenho ambiental. São exemplos de critérios não adicionais aqueles baseados em tamanho do município e da população, pois não variam em função da melhoria da gestão ambiental (Tabela 1).

Na Tabela 1 é possível verificar que apesar do aumento no número de estados que criaram legislações de ICMS-E ao longo do tempo, ainda existem 10 estados brasileiros onde tal iniciativa não foi empreendida. Observa-se também que a porcentagem da cota-parte do ICMS distribuída a partir de critérios ambientais varia entre 0,18\% (no Rio Grande do Sul) e 13\% (no Tocantins), mas o mais utilizado é 5\%.

Com a pesquisa realizada é possível destacar os estados do Amapá, Mato Grosso do Sul, Minas Gerais, Paraná, Rio de Janeiro e Tocantins, como aqueles que possuem leis de ICMS-E que mais estimulam a competição positiva entre os municípios, por remunerarem mais aqueles que incorrem em maiores gastos ambientais. Com destaque para os estados do Tocantins, que possui o maior índice de ICMS-E, e para Rio de Janeiro e Paraná, que dão maior importância para as Unidades de Conservação Municipais.

Um aspecto interessante de se estudar o ICMS-E é que as legislações estaduais mantêm seus princípios gerais, ao mesmo tempo em que possuem diferentes características e modelos. Assim, seu estudo pode identificar casos que chegam a resultados mais promissores que outros, aprimorando a utilização desta ferramenta pela gestão pública. 
Tabela 1. Características da legislação de ICMS-E nos estados que implementaram a política até janeiro de 2018.

\begin{tabular}{|c|c|c|c|c|}
\hline & CRIAÇÃO & ICMS-E & ADICIONALIDADE & $\begin{array}{l}\text { CRITÉRIOS QUE INCENTIVAM O } \\
\text { GASTO MUNICIPAL }\end{array}$ \\
\hline Acre & 2004 & $5,00 \%$ & Baixaou Inexistente & $\begin{array}{l}\text { Apesar do cálculo dos índices } \\
\text { considerar o tamanho das Unidades } \\
\text { de Conservação (UCs), o fator de } \\
\text { correção em função da área e da } \\
\text { população dá grande importância } \\
\text { ao tamanho do município e da } \\
\text { população. }\end{array}$ \\
\hline Amapá & 1996 & $1,40 \%$ & Alta & $\begin{array}{l}\text { Os critérios de repasse consideram } \\
\text { o tamanho e a qualidade das } \\
\text { áreas protegidas, e a melhoria } \\
\text { de performance em cada critério } \\
\text { aumenta a pontuação do município. }\end{array}$ \\
\hline Ceará & 2007 & $2,00 \%$ & Baixaou Inexistente & $\begin{array}{l}\text { Único estado que não possui } \\
\text { critério de UC. O cálculo do repasse } \\
\text { é baseado em critérios qualitativos } \\
\text { da gestão de resíduos sólidos, mas } \\
\text { sem variação caso haja melhoria de } \\
\text { performance em relação a um critério } \\
\text { já atendido. }\end{array}$ \\
\hline Goiás & $2011 / 14$ & $5,00 \%$ & Baixaou Inexistente & $\begin{array}{l}\text { Repasse baseado no número de } \\
\text { critérios mínimos atendidos pelo } \\
\text { município, mas sem variação caso } \\
\text { haja melhoria de performance em } \\
\text { relação a um critério já atendido. }\end{array}$ \\
\hline Mato Grosso & 2000 & $5,00 \%$ & Média & $\begin{array}{l}\text { O repasse é calculado pelo tamanho } \\
\text { das áreas protegidas dentro do } \\
\text { município. }\end{array}$ \\
\hline $\begin{array}{l}\text { Mato Grosso } \\
\text { do Sul }\end{array}$ & 1994 & $5,00 \%$ & Alta & $\begin{array}{l}\text { O repasse considera o tamanho e } \\
\text { a qualidade das áreas protegidas, } \\
\text { e a qualidade de tratamento dos } \\
\text { resíduos sólidos e da coleta seletiva. }\end{array}$ \\
\hline Minas Gerais & 1995 & $1,10 \%$ & Alta & $\begin{array}{l}\text { O repasse é calculado por critérios } \\
\text { quantitativos e qualitativos para as } \\
\text { UCs, e critérios qualitativos para o } \\
\text { sistema de tratamento e disposição } \\
\text { final de lixo e de esgoto sanitário. }\end{array}$ \\
\hline Pará & $2012 / 14$ & $8,00 \%$ & Média & $\begin{array}{l}\text { Os critérios consideram o tamanho } \\
\text { das UCs. }\end{array}$ \\
\hline Paraná & 1991 & $5,00 \%$ & Alta & $\begin{array}{l}\text { O índice de repasse é calculado } \\
\text { baseado em critérios quantitativos } \\
\text { e qualitativos (melhor desempenho } \\
\text { aumenta a pontuação), além de dar } \\
\text { maior importância às UCs municipais. }\end{array}$ \\
\hline Pernambuco & 2000 & $3,00 \%$ & Média & $\begin{array}{l}\text { Os critérios de repasse do ICMS-E } \\
\text { consideram o tamanho e a qualidade } \\
\text { das UCs, mas não consideram } \\
\text { a qualidade dos sistemas de } \\
\text { tratamento ou da destinação final } \\
\text { dos resíduos sólidos. }\end{array}$ \\
\hline
\end{tabular}


Tabela 1(cont.) - Características da legislação de ICMS-E nos estados que implementaram a política até janeiro de 2018.

\begin{tabular}{|c|c|c|c|c|}
\hline & CRIAÇÃO & ICMS-E & ADICIONALIDADE & $\begin{array}{l}\text { CRITÉRIOS QUE INCENTIVAM O } \\
\text { GASTO MUNICIPAL }\end{array}$ \\
\hline Piauí & $2008 / 16$ & $5,00 \%$ & Baixaou Inexistente & $\begin{array}{l}\text { Repasse baseado no número de } \\
\text { critérios mínimos atendidos pelo } \\
\text { município, mas sem variação caso } \\
\text { haja melhoria de performance em } \\
\text { relação a um critério já atendido. }\end{array}$ \\
\hline Rio de Janeiro & 2007 & $2,50 \%$ & Alta & $\begin{array}{l}\text { O repasse é calculado baseado em } \\
\text { critérios quantitativos e qualitativos } \\
\text { (melhor desempenho aumenta } \\
\text { a pontuação), além de dar maior } \\
\text { importância às UCs municipais. }\end{array}$ \\
\hline $\begin{array}{l}\text { Rio Grande } \\
\text { do Sul }\end{array}$ & 1997 & $0,18 \%$ & Baixaou Inexistente & $\begin{array}{l}\text { Embora nominalmente o repasse } \\
\text { descrito como ICMS-E seja de } 7 \% \text { do } \\
\text { total, o valor efetivamente transferido } \\
\text { para aos municípios pela existência } \\
\text { de áreas protegidas é de apenas } \\
0,18 \% \text { (a maior parte do repasse é } \\
\text { função da área total do município, } \\
\text { independente do seu uso ou critérios } \\
\text { ambientais). }\end{array}$ \\
\hline Rondônia & 1996 & $5,00 \%$ & Média & $\begin{array}{l}\text { Os critérios de repasse do ICMS-E } \\
\text { consideram apenas as áreas de UCs } \\
\text { no município em proporção às áreas } \\
\text { de UCs no estado. }\end{array}$ \\
\hline São Paulo & 1993 & $0,50 \%$ & Baixaou Inexistente & $\begin{array}{l}\text { Os critérios de repasse do ICMS-E } \\
\text { consideram apenas as áreas } \\
\text { protegidas estaduais e não } \\
\text { consideram critérios qualitativos de } \\
\text { gestão. }\end{array}$ \\
\hline Tocantins & 2002 & $13,00 \%$ & Alta & $\begin{array}{l}\text { O índice de repasse é baseado em } \\
\text { diversos critérios quantitativos e } \\
\text { qualitativos que variam de acordo } \\
\text { com o melhor desempenho do } \\
\text { município. }\end{array}$ \\
\hline
\end{tabular}

Fonte: Elaboração própria.

Desta forma, vários autores buscaram analisar os impactos do ICMS-E em diferentes estados. Alguns estudos estavam relacionados à compreensão do impacto do ICMS-E sobre a criação de Unidades de Conservação (Loureiro, 2002; Klein et. al, 2009; Pinto et al., 2015; Fernandes et al., 2011; Oliveira e Murer, 2010; Silva Júnior et al., 2013; Matsubara, 2017). Outros estudos apontam o impacto sobre a gestão municipal, com a criação de Conselhos Municipais de Meio Ambiente e ao estímulo à melhoria dos indicadores ambientais (Moreira, 2004; Nogueira et. al., 2013). Já outros estudos discutiam a metodologia de cálculo do ICMS-E (Reis et al., 2016). Porém, poucos estudos comparam o ICMS-E nos diferentes estados em que ele é implementado, e relacionam o incentivo aos gastos municipais com a Função Gestão Ambiental, sendo que essa é a proposta desse estudo. 


\section{METODOLOGIA}

Para a realização deste estudo foram coletados os seguintes dados de todos os municípios brasileiros, de 2012 a 2016, no Sistema de Informações Contábeis e Fiscais do Setor Público Brasileiro (Siconfi): receitas orçamentárias municipais, cota-parte do ICMS total dos municípios por estado, e despesas com a Função Gestão Ambiental.

Os dados de ICMS Ecológico (ICMS-E) foram obtidos junto às Secretarias Estaduais do Meio Ambiente e de Fazenda, nos seus sítios eletrônicos, bem como através de ligações telefônicas e mensagens eletrônicas. É importante enfatizar que ocorreu certa dificuldade na obtenção desses dados e justamente a sua falta delimitou o período do estudo. Os dados mencionados foram obtidos por município e posteriormente agregados para a realização das análises por estado. A população do município foi extraída do IBGE e o IDH dos municípios foi retirado do Atlas do Desenvolvimento Humano no Brasil (2013), elaborado pelo PNUD.

Paraná, Pernambuco e Rio de Janeiro forneceram diretamente os valores nominais de ICMS-E repassados a cada um dos seus municípios. Nos demais estados, os valores foram calculados através dos índices de ICMS-E disponibilizados na legislação estadual ou pelos gestores públicos. Todos os valores foram inflacionados para o ano de 2016 com base no deflator implícito do PIB (IBGE).

Foram realizadas estatísticas descritivas e análises de regressão por Mínimos Quadrados Ordinários (MQO) com efeitos fixos em ano e Unidade da Federação para verificar como a adoção de práticas sustentáveis pelos municípios, medidas a partir dos gastos com a Função Gestão Ambiental, é influenciada pelo recebimento de ICMS-E, pelo número de habitantes e IDH-M.

Os gastos com "Função", de acordo com o Manual Técnico de Orçamento (Brasil, 2017), são o maior nível de agregação das diversas áreas de atuação do setor público, sendo essa classificação utilizada por todos os entes federativos. As despesas com a "Função Gestão Ambiental" agregam todos os programas e ações realizados para a área, de despesas comuns até obrigatórias, incluindo salários e contribuições sociais de servidores públicos, e englobam as seguintes subfunções: 541 - Preservação e Conservação Ambiental; 542 - Controle Ambiental; 543 - Recuperação de Áreas Degradadas; 544 - Recursos Hídricos; 545 - Meteorologia (Portaria №. 42/ 1999).

Adotou-se a receita fiscal municipal total, e não apenas a receita fiscal, porque boa parte dos municípios no Brasil possuem baixa capacidade de arrecadação e dependem fortemente de transferências federais e estaduais (GOMES \& MACDOWELL, 2000). De acordo com a FIRJAN (2017), 81,7\% das cidades brasileiras não foram capazes de gerar nem $20 \%$ de suas receitas em 2016 . Além disso, do ponto de vista da alocação da despesa, o elemento mais importante para a definição do gasto ambiental do município é sua capacidade de pagamento, independente dos recursos serem provenientes de arrecadação própria ou transferências. 
Deve-se destacar, por fim, que os estados que não possuem ICMS-E foram também analisados como grupo de controle, com o objetivo de verificar se as causalidades apresentadas neste estudo se referem à transferência da cota-parte do ICMS a partir de critérios ambientais ou a uma tendência geral.

\section{RESULTADOS}

A Tabela 2 apresenta o montante total de ICMS-E repassado dos Estados para os municípios no período 2012-2016. Esses valores dependem diretamente da atividade econômica de cada estado, mas também dos coeficientes de repasse que variam bastante, conforme é possível verificar na Tabela 1. De todo modo, o valor total do repasse é significativo, atingindo R\$ 1,9 bilhões em 2016.

Tabela 2 - Valor do ICMS-E repassado aos municípios, 2012-2016 (R\$ Milhões de 2016)

\begin{tabular}{l|r|r|r|r|r}
\hline Estado & 2012 & 2013 & 2014 & 2015 & 2016 \\
\hline Acre & 7,7 & 10,1 & 12,2 & 13,1 & 12,3 \\
\hline Amapá & 3,0 & 3,4 & 2,8 & 2,4 & 2,0 \\
\hline Pará & 0 & 0 & 42,4 & 84,4 & 120,3 \\
\hline Rondônia & 45,5 & 43,6 & 41,8 & 43,9 & 40,8 \\
\hline Tocantins & 65,4 & 68,6 & 69,7 & 69,3 & 72,8 \\
\hline Ceará & 48,5 & 52,2 & 52,9 & 50,2 & 48,2 \\
\hline Pernambuco & 0 & 85,7 & 87,3 & 82,1 & 81,4 \\
\hline Piauí & 0 & 0 & 0 & 0 & 42,0 \\
\hline Goiás & 0 & 0 & 174,9 & 174,6 & 164,4 \\
\hline Mato Grosso & 97,5 & 99,6 & 101,6 & 98,8 & 105,3 \\
\hline Mato Grosso do Sul & 74,8 & 78,9 & 79,6 & 75,5 & 71,7 \\
\hline Minas Gerais & 97,1 & 102,6 & 100,3 & 91,5 & 91,9 \\
\hline Rio de Janeiro & 232,5 & 223,0 & 227,7 & 240,0 & 225,5 \\
\hline São Paulo & 146,4 & 155,1 & 171,6 & 165,8 & 152,1 \\
\hline Paraná & 300,6 & 324,9 & 321,8 & 344,0 & 323,7 \\
\hline Rio Grande do Sul & 0 & 0 & 445,1 & 435,6 & 444,6 \\
\hline TOTAL & $1.119,0$ & $1.247,6$ & $1.931,5$ & $1.971,4$ & $1.999,0$ \\
\hline & & & & & \\
\hline & 0 & & & & \\
\hline
\end{tabular}

Fonte: Elaboração própria

A primeira análise realizada foi a comparação do percentual médio de participação das despesas com a Função Gestão Ambiental sobre as despesas totais dos municípios que recebem e não recebem ICMS-E. A média desse percentual nos municípios localizados em estados que recebem ICMS-E há mais tempo (Acre, Amapá, Ceará, Mato Grosso, Mato Grosso do Sul, Minas Gerais, Paraná, Pernambuco, Rio de Janeiro, 
Rio Grande do Sul, Rondônia, São Paulo e Tocantins) é de 0,65\%, bastante superior à média de $0,28 \%$ dos municípios em estados que não têm legislação sobre o tema. Os municípios dos estados com legislação recente sobre o tema (Pará, Piauí e Goiás) encontram-se em situação intermediária, com média de 0,46\% (Tabela 3).

Tabela 3 - Média municipal de despesas com a Função Gestão Ambiental/ despesas totais, ICMS-E/ receita total, IDH-M e população, por UF, 2012/16

\begin{tabular}{|c|c|c|c|c|}
\hline UF & $\begin{array}{l}\text { Despesa Ambiental/ } \\
\text { Despesa Total (\%) }\end{array}$ & $\begin{array}{c}\text { ICMS-E/ } \\
\text { ReceitasTotais } \\
(\%)\end{array}$ & IDH-M Médio & PopulaçãoMédia \\
\hline \multicolumn{5}{|c|}{ Estados sem legislação de ICMS-E } \\
\hline Alagoas & $0,18 \%$ & $0,00 \%$ & 0,566 & 34.663 \\
\hline Bahia & $0,19 \%$ & $0,00 \%$ & 0,595 & 37.035 \\
\hline Sergipe & $0,19 \%$ & $0,00 \%$ & 0,597 & 29.813 \\
\hline Maranhão & $0,20 \%$ & $0,00 \%$ & 0,576 & 32.467 \\
\hline Paraíba & $0,32 \%$ & $0,00 \%$ & 0,588 & 17.824 \\
\hline Santa Catarina & $0,36 \%$ & $0,00 \%$ & 0,728 & 23.032 \\
\hline $\begin{array}{l}\text { Rio Grande do } \\
\text { Norte }\end{array}$ & $0,37 \%$ & $0,00 \%$ & 0,612 & 21.265 \\
\hline Roraima & $0,44 \%$ & $0,00 \%$ & 0,617 & 36.589 \\
\hline Amazonas & $0,45 \%$ & $0,00 \%$ & 0,566 & 64.183 \\
\hline Espírito Santo & $0,51 \%$ & $0,00 \%$ & 0,692 & 49.240 \\
\hline \multicolumn{5}{|c|}{ Estados com legislação de ICMS-E antiga } \\
\hline Pernambuco & $0,44 \%$ & $0,24 \%$ & 0,596 & 50.722 \\
\hline São Paulo & $0,54 \%$ & $0,34 \%$ & 0,740 & 68.262 \\
\hline Minas Gerais & $0,46 \%$ & $0,41 \%$ & 0,668 & 24.647 \\
\hline Ceará & $0,39 \%$ & $0,52 \%$ & 0,617 & 48.182 \\
\hline Amapá & $1,48 \%$ & $0,70 \%$ & 0,645 & 52.896 \\
\hline Rondônia & $0,21 \%$ & $1,23 \%$ & 0,644 & 31.155 \\
\hline Rio Grande do Sul & $0,75 \%$ & $1,25 \%$ & 0,713 & 22.626 \\
\hline Acre & $0,52 \%$ & $1,39 \%$ & 0,587 & 36.320 \\
\hline Rio de Janeiro & $1,26 \%$ & $1,54 \%$ & 0,709 & 182.451 \\
\hline Paraná & $0,87 \%$ & $1,61 \%$ & 0,702 & 27.788 \\
\hline Mato Grosso & $0,27 \%$ & $1,92 \%$ & 0,685 & 23.476 \\
\hline $\begin{array}{l}\text { Mato Grosso do } \\
\text { Sul }\end{array}$ & $0,65 \%$ & $2,03 \%$ & 0,672 & 33.966 \\
\hline Tocantins & $2,03 \%$ & $2,95 \%$ & 0,640 & 10.656 \\
\hline \multicolumn{5}{|c|}{ Estados com legislação de ICMS-E recente } \\
\hline Piauí & $0,43 \%$ & $0,00 \%$ & 0,572 & 14.754 \\
\hline Pará & $0,52 \%$ & $0,53 \%$ & 0,585 & 64.552 \\
\hline Goiás & $0,45 \%$ & $1,22 \%$ & 0,695 & 27.323 \\
\hline
\end{tabular}

Fonte: Elaboração própria 
É importante notar que, entre os estados que apresentam maior proporção de gasto municipal com a Função Gestão Ambiental estão aqueles que possuem legislações de ICMS-E com critérios qualitativos, com destaque para Tocantins, Amapá, Rio de Janeiro e Paraná. Acredita-se que essas legislações sejam mais efetivas em incentivar as prefeituras a gastarem mais com a gestão ambiental com vistas a melhorarem seu desempenho no ranking de repartição de recursos.

A média municipal da participação relativa das despesas com a Função Gestão Ambiental também foi comparada dentro de cada estado com legislação mais antiga de ICMS-E (editadas até 2007). Em todos esses estados, a média de gastos com gestão ambiental nos municípios beneficiados com ICMS-E (variando de 0,29\% a 2,03\%) é superior a dos municípios nesses mesmos estados que não recebem ICMS-E (oscilando entre $0,0 \%$ e 0,86\%). Essa é outra evidência de que o recebimento de ICMS-E está correlacionado com o gasto em gestão ambiental.

Além de indicar que há uma correlação entre a porcentagem da despesa com a Função Gestão Ambiental e a existência de legislação de ICMS-E, os dados da Tabela 3 sugerem que os gastos em gestão ambiental crescem na medida em que aumenta a participação relativa do ICMS-E na receita total do município.

Essa tendência é percebida na Tabela 4, que distribui os municípios, por decil, em função da participação relativa do ICMS-E na sua receita total. Porém, essa relação não é linear, e a proporção dos gastos com a Função Gestão Ambiental só passa a ser mais significativa quando a participação do ICMS-E assume uma proporção maior sobre suas receitas totais. Isso significa que municípios que recebem relativamente pouco ICMS-E em relação às suas receitas totais têm média de gastos ambientais pouco maior do que os municípios que não recebem ICMS-E, mas essa relação fica mais evidente nos decis superiores. Igualmente nota-se que o incremento de gastos com a Função Gestão Ambiental é pequeno se comparado com o aumento da participação do ICMS-E na receita total.

É interessante notar que o tamanho da população apresenta relação inversa com a proporção das despesas com gestão ambiental. Municípios maiores tendem a apresentar uma relação menor entre o ICMS-E e a receita total em função da diversificação e escala de receitas recebidas, inclusive por arrecadação própria. Isso explica a relação inversa entre tamanho da população e a participação do ICMS-E na receita total. Por outro lado, por lidar com problemas ambientais mais complexos, em função da maior concentração e densidade urbana, esses municípios tendem a gastar mais em gestão ambiental. Além disso, em um país heterogêneo como o Brasil, não se deve desconsiderar os efeitos dos diferenciais de desenvolvimento humano entre os municípios.

Para compreender melhor a correlação dos gastos ambientais com o repasse de ICMS-E, foi efetuada uma análise de regressão considerando a variável dependente "Gasto Ambiental/Despesa Total" (Regressão 1), que é a proporção dos gastos municipais com a Função Gestão Ambiental em relação a despesa total do município, 
e a variável dependente "Gasto Ambiental" (Regressão 2), que é apenas o montante gasto com a Função Gestão Ambiental. Como variáveis explicativas foram utilizadas as variáveis "ICMS-E/Receita Total" (Regressão 1), que é a participação do repasse estatal de ICMS-E nas receitas totais do município, e a variável "ICMS-E" (Regressão 2), que representa o total repassado ao município pelos critérios ambientais da lei de ICMS. Como variáveis de controle foram usados o IDH-M e a população do município, além dos controles dos efeitos fixos de ano e Estados. A Tabela 5 apresenta os resultados das regressões.

Tabela 4 - Média municipal de despesas com a Função Gestão Ambiental/despesas totais, ICMS-E/ receita total, IDH-M e população, por decil da proporção ICMS-E/receita total, 2012/16

\begin{tabular}{|c|c|c|c|c|}
\hline & $\begin{array}{l}\text { Gasto Ambiental/ } \\
\text { Despesa Total }\end{array}$ & $\begin{array}{c}\text { ICMS-E/ } \\
\text { ReceitasTotais }\end{array}$ & IDH-M & População \\
\hline \multicolumn{5}{|c|}{ Estados sem legislação de ICMS-E } \\
\hline Média & $0,28 \%$ & $0,00 \%$ & 0,620 & 30.819 \\
\hline \multicolumn{5}{|c|}{ Estados com legislação de ICMS-E recente } \\
\hline Média & $0,46 \%$ & $0,63 \%$ & 0,627 & 29.856 \\
\hline \multicolumn{5}{|c|}{ Estados com legislação de ICMS-E antiga } \\
\hline NãoRecebem & $0,45 \%$ & $0,00 \%$ & 0,697 & 21.463 \\
\hline Decil $1(0-10 \%)$ & $0,71 \%$ & $0,02 \%$ & 0,705 & 243.959 \\
\hline Decil 2 (10-20\%) & $0,84 \%$ & $0,12 \%$ & 0,701 & 85.028 \\
\hline Decil $3(20-30 \%)$ & $0,64 \%$ & $0,25 \%$ & 0,681 & 36.761 \\
\hline Decil 4 (30-40\%) & $0,64 \%$ & $0,40 \%$ & 0,671 & 35.101 \\
\hline Decil 5 (40-50\%) & $0,62 \%$ & $0,58 \%$ & 0,665 & 29.146 \\
\hline Decil 6 (50-60\%) & $0,68 \%$ & $0,83 \%$ & 0,666 & 24.906 \\
\hline Decil 7 (60-70\%) & $0,68 \%$ & $1,18 \%$ & 0,677 & 16.638 \\
\hline Decil 8 (70-80\%) & $0,78 \%$ & $1,75 \%$ & 0,676 & 14.404 \\
\hline Decil 9 (80-90\%) & $0,96 \%$ & $2,79 \%$ & 0,666 & 13.324 \\
\hline Decil 10 (90-100\%) & $1,31 \%$ & $8,03 \%$ & 0,668 & 12.189 \\
\hline
\end{tabular}

Fonte: Elaboração própria

Na "Regressão 1" da Tabela 5, a proporção de gastos com a Função Gestão Ambiental é significativamente correlacionada com a participação do ICMS-E nas receitas totais dos municípios. O coeficiente na casa de $6 \%$ indica que, em média, para cada ponto percentual de "ICMS-E/Receitas Totais" repassado ao município, o gasto em gestão ambiental é 0,06\% maior. A "Regressão 2" também apresenta resultado positivo e significativo entre o repasse de ICMS-E e o montante de gasto ambiental do município. O coeficiente da variável "ICMS-E" indica que, em média, para cada real repassado pelas legislações de ICMS-E aos municípios, o gasto em gestão ambiental 
é $\mathrm{R} \$$ 0,16 maior. Em ambas as regressões, quanto maior o IDH-M e a população do município, maior é o gasto em gestão ambiental.

Por fim, para entender melhor como os municípios dos estados que recebem ICMS-E comprometem seu gasto em gestão ambiental em contraste com os estados sem ICMS-E, foi realizada a "Regressão 3" - apresentada na Tabela 6. Os estados que não tem legislação de ICMS-E foram omitidos, de forma que os coeficientes na "Regressão 3" são valores em referência à média de todos esses estados: por exemplo, se o coeficiente de um estado é 0,01, os municípios desse estado têm, em média, um gasto de 0,01 ponto percentual maior que a média dos estados sem legislação de ICMS-E.

Na tabela 6, observa-se que os estados que apresentam os efeitos fixos significativos mais altos são os mesmos que apresentam as maiores médias de gastos municipais com a Função Gestão Ambiental:Tocantins, Amapá, Rio de Janeiro e Paraná (conforme a Tabela 3). Esse resultado também corrobora a hipótese de que a legislação de ICMS-E é indutora de gastos municipais em gestão ambiental, e que a forma pela qual os critérios de partilha são estabelecidos pode aumentar essa indução: como dito anteriormente, as leis de ICMS-E de Tocantins, Rio de Janeiro, Amapá e Paraná são legislações com alto grau de adicionalidade (Tabela 1). Apesar desses coeficientes de efeito fixo dos estados captarem a influência de outras variáveis omitidas, há grande correlação entre os coeficientes do estado da "Regressão 3" e o grau de adicionalidade: enquanto estados com alta adicionalidade têm os maiores coeficientes (Tocantins, Amapá, Rio de Janeiro, Paraná), estados com baixo ou inexistente grau de adicionalidade têm coeficientes muito menores (São Paulo, Ceará, Goiás).

Tabela 5- Resultado das análises de regressão

\begin{tabular}{l|r|r}
\hline Variáveis Independentes & Regressão 1 & Regressão 2 \\
\hline ICMS E/Receitas Total & $\begin{array}{r}\text { Gasto Ambiental/ } \\
\text { Despesa Total }\end{array}$ & Gasto Ambiental \\
\hline ICMS E & $0.0640^{* * *}$ & $0.157^{* * *}$ \\
\hline In (IDH-M) & $0.0113^{* * *}$ & $1.236 \mathrm{e}+06^{* * *}$ \\
\hline In (População) & $0.00142^{* * *}$ & $541,451^{* * *}$ \\
\hline ReceitasTotais & & $0.00604^{* * *}$ \\
\hline EfeitoFixo de Ano & $-0.000435^{* *}$ & $-129,143^{*}$ \\
\hline $\begin{array}{l}\text { Constante } \\
\text { Observações }\end{array}$ & $-0.00375^{* * *}$ & $-4.377 e+06^{* * *}$ \\
\hline$R^{2}$ & 26,390 & 26,390 \\
\hline $\begin{array}{l}\text { Erros padrão robustos } \\
\text { ntre parênteses: } *^{* * *} \mathrm{p}<0.01,\end{array}$ & 0.121 & 0.669 \\
\hline p $<0.05,{ }^{*} \mathrm{p}<0.1$ & & \\
\hline
\end{tabular}

Fonte: Elaboração própria 
Tabela 6 - Resultados da Regressão 4, incluindo efeitos fixos de estados

\begin{tabular}{|c|c|}
\hline Variáveis Independentes & Regressão 3 \\
\hline & $\begin{array}{c}\text { Gasto Ambiental/ } \\
\text { Despesa Total }\end{array}$ \\
\hline In (IDH-M) & $0.00696^{* * *}$ \\
\hline In (População) & 0.000102 \\
\hline In (ReceitasTotais) & $0.00155^{* * *}$ \\
\hline Rondônia & $-0.00133^{* *}$ \\
\hline Acre & $0.00269^{* * *}$ \\
\hline Pará & $0.00152^{* * *}$ \\
\hline Amapá & $0.01170^{* * *}$ \\
\hline Tocantins & $0.01850^{* * *}$ \\
\hline Piauí & $0.00317^{* * *}$ \\
\hline Ceará & 0,00037 \\
\hline Pernambuco & $0.00109 * * *$ \\
\hline Minas Gerais & $0.00163^{* * *}$ \\
\hline Rio de Janeiro & $0.00611^{* * *}$ \\
\hline São Paulo & $0.000515^{*}$ \\
\hline Paraná & $0.00496^{* * *}$ \\
\hline Rio Grande do Sul & $0.00395^{* * *}$ \\
\hline Mato Grosso do Sul & $0.00228^{* * *}$ \\
\hline Mato Grosso & $-0.000884^{* *}$ \\
\hline Goiás & $0.00108^{* * *}$ \\
\hline EfeitoFixo de Ano & $-0.000502^{* *}$ \\
\hline Constante & $-0.0218^{* * *}$ \\
\hline Observações & 26,390 \\
\hline $\mathrm{R}^{2}$ & 0.112 \\
\hline $\begin{array}{l}\text { Erros padrão robustos entre } \\
\text { parênteses: }{ }^{* *} p<0.01 \text {, } \\
{ }^{*} p<0.05,{ }^{*} p<0.1\end{array}$ & \\
\hline
\end{tabular}

Fonte: Elaboração própria

\section{CONSIDERAÇÕES FINAIS}

O objetivo deste trabalho foi investigar se há alguma influência do ICMS Ecológico na despesa ambiental do município. Foram realizados diferentes exercícios estatísticos com o percentual da despesa com a Função Gestão Ambiental dos municípios sobre sua despesa total em relação a variáveis como ICMS-E em proporção da receita total municipal, população e IDH-M. 
Os resultados deste trabalho confirmam que o estabelecimento de uma política pública de incentivos positivos - no caso, o repasse de ICMS-E - pode ser efetiva para estimular os municípios a ampliarem os gastos com gestão ambiental. Há significância estatística na correlação entre proporção do gasto municipal com a Função Gestão Ambiental e a relação entre ICMS-E e as receitas totais do município.

Por outro lado, chama atenção a baixa sensibilidade do crescimento da despesa com a Função Gestão Ambiental como proporção da despesa total em relação ao aumento do ICMS-E na receita total do município. Isso indica que a efetividade do ICMS-E como fomentador do gasto em gestão ambiental é ainda pequena.

Essa influência do ICMS-E sobre ações municipais de gestão ambiental pode ser aumentada se o desenho da legislação estadual favorecer critérios que estimulem as prefeituras a investir na melhoria da sua gestão ambiental para obter maiores repasses, pagando mais para aqueles que investirem mais. Isso é evidenciado pela maior correlação entre proporção de gastos com a Função Gestão Ambiental sobre os gastos totais municipais nos estados onde a adicionalidade alta foi identificada, fomentando a competição positiva entre municípios. Do mesmo modo, percebese que nos estados onde a melhoria da gestão ambiental traz pouco retorno para a prefeitura, em termos de incremento de recebimento de ICMS-E, a relação com a proporção do gasto ambiental é menor.

\section{||||||||||||||||||||||||||||||||||||||||||||||||||||||||||||||||||||||||||||||||}


A escala do repasse do ICMS-E também importa: identificou-se que a correlação entre proporção de gastos com a Função Gestão Ambiental e a importância relativa do ICMS-E na receita municipal se torna bem mais evidente quando o valor do último ultrapassa $1 \%$. Ou seja, a parcela do ICMS-E a ser repassado para o município não pode ser pequena demais, pois isso desestimula a resposta por parte dos gestores locais.

Outros fatores também influenciam a decisão do gasto público em gestão ambiental, como o tamanho da população e seu nível de desenvolvimento humano. Uma trajetória de aumento da urbanização e do IDH-M pode induzir a um aumento da importância da política da gestão ambiental. Contudo, não é possível esquecer a importância dos gastos com a Função Gestão Ambiental nos municípios menores e/ ou de menor desenvolvimento, mas que recebem maiores repasses de ICMS-E em relação a suas receitas totais.

Este artigo mostrou que ICMS-E é um instrumento importante de coordenação entre as intenções dos estados e as ações municipais. Porém, as principais dificuldades para que essa política seja bem sucedida em ampliar os gastos municipais na gestão ambiental são: a elaboração de uma legislação que estimule a ampliação do gasto municipal em meio ambiente e a divulgação ampla desta política.

O primeiro desafio deve ser enfrentado nas assembléias estaduais que devem privilegiar a competição positiva entre os municípios, de forma que eles recebam mais recursos se investirem mais em gestão ambiental, tendo em vista critérios quantitativos e qualitativos. O segundo desafio pode ser encarado no âmbito da gestão estadual, ampliando a comunicação aos municípios a respeito dos objetivos da política, seus critérios e cálculos. Isso porque, a pouca transparência e falta de comunicação não favorece a coordenação.

De qualquer maneira, o ICMS-E se mostrou um mecanismo efetivo no estímulo ao aumento dos gastos ambientais, ainda que com baixa elasticidade, influenciando positivamente a tomada de decisão dos agentes públicos. Esse tipo de construção pode ser estendido a outros problemas do desenvolvimento e esferas administrativas: criar sistemas de incentivos positivos, como participação orçamentária, acesso a fundos públicos ou outras formas de incentivo econômico, pode induzir à mudança de comportamento de agentes públicos e privados, e a melhoria da qualidade de vida da população. 


\section{Referências}

ABRUCIO, F. L. A coordenação federativa no Brasil: a experiência do período $\mathrm{FHC}$ e os desafios do governo Lula. Revista de Sociologia e Política, 24, p. 41-67, 2005.

ARRETCHE, M. Federalismo e Políticas Sociais no Brasil: Problemas de Coordenação e Autonomia. In: Saravia, E. \& Ferrarezi, E. Políticas públicas; coletânea. Brasília: ENAP, 2006.

ATLAS BRASIL (2013). Atlas do Desenvolvimento Humano no Brasil 2013. Consulta. Disponível em: http://www.atlasbrasil.org.br/2013/pt/consulta/. Acesso em: maio 2018.

BRASIL (1988). Constituição da República Federativa do Brasil: promulgada em 5 de outubro de 1988. Acesso em: maio 2018.

BRASIL. Ministério do Planejamento, Desenvolvimento e Gestão. Secretaria de Orçamento Federal. Manual Técnico de Orçamento - MTO. Edição 2018. Brasília, 2017.

BOUCKAERT, G.; PETERS, G. \&VERHOEST, K. The Coordination of Public Sector Organizations: Shifting Patterns of Public Management. Basingstoke: PalgraveMacmillan, 2010.

CASTRO, B. S. \& YOUNG, C. E. F. Problemas de coordenação de políticas públicas: desafios para a gestão ambiental no Brasil. Revista Síntese (TCE-RJ), v. 12, n. 1, 32-53, 2017.

GOMES, G. M. \& MAC DOWELL, M. C. Descentralização Política, Federalismo Fiscal e Criação de Municípios: O que é Mau para o Econômico nem sempre é Bom para o Social. Texto para discussão n. 706. Instituto de Pesquisa Econômica Aplicada. Brasília, fevereiro, 2000.

FERNANDES, L. L.; COELHO, A. B.; FERNANDES, E. A. \& LIMA, J. E. Compensação e incentivo à proteção ambiental: o caso do ICMS Ecológico em Minas Gerais. Revista de Econonomia e Sociologia Rural, v. 49, n. 3, p. 521-544, 2011.

FIRJAN. IFGF - Índice Firjan de Gestão Fiscal 2017: Ano Base 2016. Recorte Municipal Abrangência Nacional. Elaboração do Estudo GEE - Gerência de Estudos Econômicos. Agosto/2017. Disponível em: https://bit.ly/2kylJCf. Acesso em: maio 2018.

KLEIN, F. B.; SOUZA, M. S. \& ALMEIDA, P. S. Análise sobre a eficiência socioeconômica e ambiental no uso do ICMS Ecológico no Estado de São Paulo. In: AUGM Ambiente 2009 - VI Congresso de Maio Ambiente da AUGM Associação de Universidades Grupo de Montevidéu, 2009, São Carlos - SP. VI Congresso de Maio Ambiente da AUGM Associação de Universidades Grupo de Montevidéu, 2009. Disponível em: http://www.ambiente-augm.ufscar.br/uploads/ A3-095.pdf

LOUREIRO, W. Contribuição do ICMS Ecológico à conservação da biodiversidade no Estado do Paraná. Tese (Doutorado) - Curso de Pós-Graduação em Engenharia Florestal, Universidade Federal do Paraná. Curitiba, 2002.

MACIEL, V. F., DE TOLEDO PIZA, C. C. \& PENOFF, R. N. Desigualdades regionais e bem-estar no Brasil: quão eficiente tem sido a atividade tributária dos estados para a sociedade? Planejamento e Políticas Públicas, n. 33, p. 291-318, julho-dezembro, 2010.

MALONE, T. W. \& CROWSTON, K. The interdisciplinary study of coordination. ACM Computing Surveys (CSUR), v. 26, n. 1, p. 87-119, 1994.

MATSUBARA, A. T. ICMS Ecológico e a Conservação de Áreas Protegidas no Estado do Tocantins: Um Enfoque nas Terras Indígenas. Dissertação - Programa de Pós-Graduação em Ecologia de Ecótonos, da Universidade Federal do Tocantins. Porto Nacional - Tocantins, Março 2017.

METCALFE, L. (1996). Building capacities for integration: the future role of the Commission. Eipascope, n. 2, p. 1-11, 1996.

MINTZBERG, H. Criando organizações eficazes: estruturas em cinco configurações. 2. ed. $4^{\circ}$. reimpressão, São Paulo: Ed. Atlas, 2008. 
MOREIRA, A. D. A gestão do ICMS ecológico em Mato Grosso do Sul. Dissertação (de mestrado) Universidade para o Desenvolvimento do Estado e da Região do Pantanal Campo Grande, 2004.

NOGUEIRA, C. A. G.; MONTEIRO, M. A. P. \& MAZZA, A. C. A. Uma análise da consistência do ICMS ecológico do Ceará enquanto mecanismo de incentivos e redistribuição de recursos financeiros. Revista Ciências Administrativas, Fortaleza, v. 19, n. 2, p. 446-475, 2013.

OLIVEIRA, T. V. M. \& MURER, Y. C. O ICMS Ecológico e a implementação de políticas públicas ambientais no estado de Rondônia. Revista do Direito Público, v. 5, n. 1, 185-216, 2010.

PINTO, J. S.; FRAINER, D. M.; OLIVEIRA, A. K. M. \& SOUZA, C. C. Diagnóstico e avaliação da eficiência da preservação do ambiente em Mato Grosso do Sul a partir da inclusão do pagamento de serviços ambientais. Desenvolvimento e Meio Ambiente, n. 35, p. 225-240, 2015.

REIS, E. A.; LAGO, D. V. \& ARAUJO, A. C. P. S. Diagnóstico da composição e evolução da arrecadação do ICMS Ecológico no município do Rio de Janeiro. Anais $5^{\circ}$ Simpósio de Gestão Ambiental e Biodiversidade, 21 a 23 de junho, 2016.

RIBEIRO, C. A.; ROSSATO, M. V.; GUSE, J. C.; FREITAS, L. A. R. \& DORR, A. C. ICMS Ecológico: uma abordagem à gestão ambiental nos municípios do Rio Grande do Sul. Revista Sociais e Humanas, v. 26, n. 2, 2013.

SILVA JÚNIOR, L. H.; PEDROSA, B. M. J.; SILVA, M. F. Avaliação dos Impactos do ICMS Socioambiental na Criação de Unidades de Conservação e Unidades de Tratamento de Resíduos Sólidos em Pernambuco: Uma Análise a partir do Método de Diferenças em Diferenças. Revista Econômica do Nordeste, v. 44, n. 2, p. 557-572, 2013.

Sistema de Informações Contábeis e Fiscais do Setor Público Brasileiro (SICONFI). Disponível em: https://siconfi.tesouro.gov.br/siconfi/index.jsf. Acesso em: jan. 2018.

UHLMANN,V. O.; ROSSATO, M. V. \& PFITSCHER, E. D. Conhecimento dos gestores públicos sobre o instrumento de política pública ICMS ecológico nos municípios da quarta colônia de imigração italiana do RS. Enfoque: Reflexão Contábil. UEM - Paraná, v. 29, n. 2, p. 83-102, 2010.

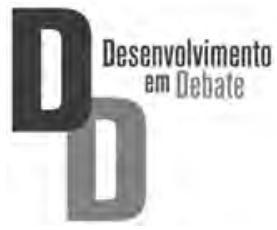

